\title{
Matrioskas na floresta: uma agenda de pesquisa sobre Meta-Organizações na Amazônia
}

Matrioskas in the forest - a research agenda on Meta-Organizations in the Amazon

\author{
José Augusto Lacerda Fernandes ${ }^{1}$ \\ Fernando Dias Lopes ${ }^{2}$
}

\begin{abstract}
Resumo:
Desafios de elevada complexidade, como a sustentabilidade da maior floresta tropical do planeta, a Amazônia, têm demandado arranjos organizacionais inovadores, capazes de articular esforços coletivos em prol de problemas comuns. Ao reunir várias organizações em sua composição, meta-organizações têm conseguido disseminar e fortalecer práticas sustentáveis em diferentes contextos e setores, destacando-se como plataformas de governança alinhadas com grandes desafios da contemporaneidade. Apesar da importância dessas formas organizacionais para a literatura e para a sociedade, há uma lacuna expressiva de conhecimento sobre a atuação delas na região amazônica. Com o objetivo de propor uma agenda de pesquisa que aborde tal demanda, este artigo: i) apresenta uma revisão sistemática dos estudos sobre metaorganizações relacionados à sustentabilidade, desde o surgimento do conceito, em 2005, até o ano de 2020; ii) identifica um conjunto de problemas característicos da Amazônia brasileira; e, por fim, iii) descreve diferentes propostas de investigação que relacionam meta-organizações a desafios do contexto amazônico. Assim, este trabalho não somente pavimenta um caminho oportuno para o desenvolvimento teórico do tema, como ampara os esforços de diferentes atores engajados com o exame crítico, a formação e a gestão de meta-organizações, em especial, naquelas que têm atuado, direta ou indiretamente, nessa região tão importante quanto ameaçada do globo.
\end{abstract}

Palavras-chave: Meta-Organizações; Amazônia; Sustentabilidade

\begin{abstract}
:
Grand challenges, such as the sustainability of the largest tropical forest on the planet, the Amazon, have demanded the formation of alternative forms of organization capable of articulating collective efforts in favor of common problems. In different contexts, meta-organizations, that is, organizations formed by other organizations, have managed to disseminate and strengthen sustainable practices, thus standing out as governance platforms aligned with the grand challenges of contemporaneity. Despite the importance of these
\end{abstract}

\footnotetext{
${ }^{1}$ Professor da Faculdade de Administração (FAAD) e do Mestrado em Gestão Pública do Núcleo de Altos Estudos Amazônicos (PPGGP/NAEA) da Universidade Federal do Pará (UFPA) E-mail: lace rda.fernandes@gmail.com

2 Professor Titular da Escola de Administração da Universidade Federal do Rio Grande do Sul (EA/UFRGS)E-mail: fernando.lopes@ufrgs.br
} 
initiatives in the literature of organizational studies and for society, there is still a significant knowledge gap about the role of meta-organizations in the Amazon region. Intending to propose a research agenda that addresses this demand, this paper: i) presents a systematic review of studies on meta-organizations linked to sustainability, since the concept's emergence in 2005, until the year 2020; ii) identifies a set of urgent problems in the Brazilian Amazon; and, finally, iii) describes different research proposals relating meta-organizations to challenges in the Amazon context. Thus, this paper not only paves an opportune path for the theoretical development of the theme, as supports the efforts of different actors engaged with the critical examination, training, and management of metaorganizations, in particular, those who have act directly or indirectly in this so strategic like threatened region of the world.

Keywords: Meta-organizations; Amazon region; Sustainability.

\section{Introdução}

Os desafios contemporâneos têm demandado novas formas organizacionais (GEORGE et al., 2016; MAIR et al., 2016), pois, ao engendrar estruturas, práticas e processos inovadores, elas têm conseguido lidar com as dificuldades típicas dos grandes problemas da atualidade. Esse movimento tem uma relevância ímpar para os debates sobre o desenvolvimento sustentável da Amazônia. Primeiro, pelos obstáculos presentes na região serem avessos a simplismos (MITSCHEIN, ROCHA e VASCONCELLOS SOBRINHO, 2013). Segundo, porque, a julgar pelo processo de formação socioeconômica da Amazônia e pela condição na qual ela se encontra, as organizações "tradicionais" parecem não só ter sido incapazes de conduzir à sustentabilidade, como, por vezes, serem responsáveis pela conjuntura atual. Metaforicamente falando: nessa região paradoxalmente pobre, já caracterizada como "fora do estado de direito" (FEARNSIDE, 2007. p.601), tanto "o filme" da história, quanto a "foto" do presente, convocam o estudo e a adoção de novos modelos de organização.

Esse apelo se direciona, sobretudo, às formas calcadas na cooperação, visto que, ao reunir distintos saberes, perspectivas e recursos (humanos, financeiros e tecnológicos), elas têm conseguido prover soluções mais alinhadas com os desafios enfrentados na atualidade (SELSKY e PARKER, 2005; FERRARO et al., 2015). Com destaque para as meta-organizações, arranjos formados, essencialmente, por outras organizações, e não por indivíduos (AHRNE e BRUNSSON, 2005). Diferente das "organizações tradicionais", elas trazem a noção de coletividade em seu cerne (AHRNE e BRUNSSON 2011; BERKOWITZ e BOR, 2018), propiciando uma capacidade distinta na transição à sustentabilidade (BERKOWITZ, 2018).

Embora meta-organizações possam envolver atores muito distintos, não somente entre si, mas também em relação a própria organização principal, trata-se sempre de outra organização, o que nos remete às matrioskas, as famosas bonecas russas preenchidas por versões menores de si mesmas. Curiosamente, elas também são conhecidas pela capacidade de realizar desejos profundos, a exemplo da tão almejada transição à sustentabilidade, tema abordado nesse trabalho. De estudos na indústria de petróleo (RADNEJAD et al., 2017) a análises comparativas em países como Nepal, Paquistão e Gana (CHAUDHURY et al., 2016), a literatura tem observado a atuação de meta-organizações na difusão de práticas sustentáveis. A partir de um estudo na cadeia produtiva do óleo de palma, Carmagnac e Carbone 


\section{NAQ}

(2018) mostram, inclusive, como esses princípios de sustentabilidade podem ir além dos produtores e distribuidores de um único setor, alcançando outros segmentos e atores distantes.

Em meio a tais evidências, é preocupante observar a escassez de conhecimento sobre a atuação de metaorganizações na Amazônia, região que, há tantas décadas, urge por um modelo de desenvolvimento sustentável, e que, cada vez mais, é assombrada pelos riscos da savanização (LOVEJOY e NOBRE, 2018). Embora essas organizações sejam reconhecidas pelo seu dinamismo na abordagem de vazios institucionais e de mercado típicos de contextos complexos (VALENTE e OLIVER, 2018), como é o caso da Amazônia, não parece cabível admitir que o enfrentamento dos desafios locais prescinde conhecimentos qualificados sobre suas dinâmicas. Por outro lado, se observarmos que essas configurações particulares já estão atuando na Amazônia há muitas décadas, é premente saber o que elas têm produzido, como elas vêm se desenvolvendo e se relacionado com os problemas da região.

Respondendo tal chamado, este artigo delineia uma agenda de pesquisa relacionando o trabalho de metaorganizações com alguns desafios urgentes da Amazônia. A partir de uma revisão sistemática dos estudos sobre meta-organizações ligados a sustentabilidade e do mapeamento de problemas salientes na região, fez-se um conjunto de propostas que, além de encorajar pesquisas engajadas com questões socioambientais, reforçando assim o chamado por uma academia sustentável (BERKOWITZ e DELACOUR, 2020), também amparam esforços teóricos-analíticos empreendidos em torno dessas formas inovadoras de governança, cujo campo ainda "está se abrindo" (BERKOWITZ e DUMEZ, 2016).

Por meio dessas pesquisas, acadêmicos poderão diversificar o conhecimento existente sobre metaorganizações, deveras restrito ao contexto anglo-saxônico, e prover uma compreensão sobre as especificidades institucionais e locais que condicionam a atuação desses arranjos. Em especial, no que se refere ao entendimento de fenômenos subjacentes, afetados e produzidos por essas "organizações de organizações", auxiliando não somente acadêmicos, quanto outros profissionais engajados com o desenvolvimento sustentável da região.

\section{Referencial teórico-empírico}

\subsection{Meta organizações - particularidades e contribuições à sustentabilidade}

Apesar de designar um fenômeno recorrente, qual seja, a associação de várias organizações em uma organização, esse arranjo tem merecido um tratamento teórico específico por conta de algumas particularidades e dinâmicas distintas. Segundo Ahrne e Brunsson (2005), esse modelo de filiação organizacional faz com que o recrutamento e a manutenção dos membros sejam mais estratégicos do que em organizações tradicionais, pois há uma série de custos e riscos atrelados à perda de um participante específico, a exemplo de organizações de referência em um campo de atuação, ou ainda, de atores que aportam recursos fundamentais para a sobrevivência da organização. Em suma, "meta-organizações dependem de seus membros de um jeito totalmente distinto das organizações baseadas em indivíduos" (BERKOWITZ e DUMEZ, 2015, p.154).

Como desdobramento dessa relação distinta com seus membros, meta-organizações tendem a basear seus processos decisórios no consenso, e não em relações hierárquicas. O que, por um lado, acaba influenciando o tempo de resposta dessas organizações, ocasionando uma certa lentidão aos seus processos, mas, por outro, facilita a criação, o estabelecimento e a disseminação de regras comuns e padrões de 


\section{소요}

comportamentos coletivos a nível de setor (BERKOWITZ e DUMEZ, 2016). Ao relembrar meta-organizações surgidas no bojo de standars específicos, como é o caso da Extractive Industry Transparency Initiative (EITI) ou da Voluntary Principles for Security and Human Rights, esses autores destacam, inclusive, que esse traço peculiar tem propiciado uma legitimidade expressiva às decisões tomadas no âmbito de metaorganizações, o que, de certo modo, facilita sua atuação na transição à sustentabilidade.

Outra diferença latente desses arranjos reside nas relações de competição que podem se estabelecer, não somente entre os seus membros, como também entre eles e a própria organização. Embora esse aspecto não seja necessariamente negativo, ele agrega uma certa dose de incerteza à dinâmica desses arranjos (AHRNE e BRUNSSON, 2005). Por outro lado, essas organizações costumam se beneficiar de um baixo custo de manutenção, pois não precisam de estruturas operacionais vultosas e, em muitos casos, contam com colaboradores vinculados às organizações membro. Graças a isso, algumas meta-organizações chegam a ter uma abrangência global com orçamentos bastante reduzidos, o que também explica o porquê de "meta-organizações fantasmas", ou seja, de arranjos que, mesmo estando inativos, não encerram formalmente suas atividades, e ainda, a coexistência de diferentes meta-organizações com missões e agendas semelhantes em vários setores (BERKOWITZ, 2016).

Essa pequena-grande alteração na composição organizacional também implica resultados particulares. Diferentemente de organizações baseadas em indivíduos, focadas, predominantemente, na provisão de produtos e serviços, meta-organizações costumam produzir boas práticas, padrões e guias de comportamento. Estudos realizados no setor de petróleo e gás demonstraram, inclusive, como isso tem sido relevante para implementação de padrões de responsabilidade socioambiental, ajudando a materializar o conceito de desenvolvimento sustentável em contextos complexos (BERKOWITZ, 2015). Segundo alguns pesquisadores, esse foco diferenciado de atuação tem proporcionado às meta-organizações uma capacidade distinta de moldar seus próprios ambientes de atuação e, não raro, de reduzir as incertezas existentes nesses espaços (BERKOWITZ e BOR, 2018).

Em conjunto, as peculiaridades destacadas na literatura sustentam a pertinência do conceito a alegação de que há uma sub-teorização das meta-organizações (AHRNE e BRUNSSON, 2005). O que não pode ser naturalizado, pois a perpetuação de transposições teóricas inadequadas (BERKOWITZ e DUMEZ, 2016) possui rebatimentos na gestão dessas organizações, as quais contemplam uma constelação de iniciativas, e não somente associações comerciais, como pode se pensar a priori (BERKOWITZ e BOR, 2018).

Outro ponto igualmente importante reside nos desdobramentos dessas particularidades não só para a dinâmica, mas também para os resultados obtidos por meta-organizações. Ao favorecer o intercâmbio de conhecimentos, recursos e informações estratégicas, essas características têm originado espaços interorganizacionais propícios à colaboração entre diferentes atores, independente de serem competidores ou de atuarem em setores distintos (KARLBERG e JACOBSSON, 2015; BERKOWITZ e BOR, 2018). O que tem Ihes permitido um reconhecimento como formas organizacionais de alto nível e como mecanismos inovadores de governança, capazes de articular e organizar esforços coletivos, lidar com problemas em múltiplos níveis e enfrentar problemas complexos ligados à sustentabilidade (BERKOWITZ, 2018; CARMAGNAC e CARBONE, 2019; CHAUDHURY et al., 2016).

Apesar das vantagens proporcionadas por estruturas meta-organizacionais, é vital frisar que, ao abarcarem organizações distintas, e cujo as visões podem diferir frontalmente, esses arranjos também estão suscetíveis a determinados problemas, como a falta de comprometimento dos membros e o conflito de lógicas institucionais. Em um estudo recente sobre a International Whaling Commission, organização focada na proteção das baleias, mostrou-se como ordens sociais incompatíveis surgem entre a meta-organização e seus membros, afetando a sua capacidade de tomada de decisão e, por conseguinte, o alcance dos objetivos institucionais que Ihe originaram (BERKOWITZ e GROTHE-HAMMER, 2021). O que ressalta ainda 
mais o valor de estudos sobre a atuação dessas formas organizacionais na Amazônia, região cujo próprios desafios já não são poucos brevemente descritos a seguir.

\subsection{Amazônia - o retrato em $3 \times 4$ de um grande desafio}

Embora se estenda pelos territórios de nove países soberanos, a Amazônia pode ser vista como uma região universal e um bem comum global (BROMLEY e COCHRANE, 1994). Pois ao possuir uma reserva incomparável de biodiversidade e um quinto de toda a água doce disponível na Terra, essa floresta tropical presta importantes serviços ecossistêmicos, podendo determinar os rumos e a própria sobrevivência da espécie humana (ARAGÓN, 2018). Daí a noção de que, independente da nacionalidade, "somos todos amazônidas", como aponta o percursor da noção de eco-desenvolvimento (SACHS, 2008, p.1).

Aproximadamente $60 \%$ de todo bioma está localizado no Brasil, país cujo território também é preenchido majoritariamente pelo que se convencionou chamar de Amazônia Legal: uma área administrativa de 5.2 milhões de km2 que compreende nove estados da federação brasileira. Contudo, nem a relevância global e nem a representatividade geográfica local parecem ter impedido o Estado brasileiro de manter uma postura tecnocrática, autoritária e profundamente ambígua em relação à Amazônia (LIMA E BUSZYNSKI, 2011). Após tantos projetos de integração e desenvolvimento malfadados (mineração, hidroelétricas, rodovias e agronegócio), a região consolidou-se como um palco de contradições sociais, econômicas e políticas, no qual se explora e expropria o trabalho, as riquezas naturais, os valores e os saberes dos povos da floresta (CASTRO, 2010).

Essa lógica tem gerado um mosaico de problemas que, em meio a uma economia globalizada, e num país dependente do mercado de commodities como o Brasil, têm intensificado a degradação da Amazônia. Apesar de acordos multilaterais (SANTILLI et al., 2005), mecanismos de controle mais robustos, da criação de políticas ambientais, e, até mesmo, de melhorias pontuais que permitiram projetar o fim do desmatamento (NEPSTAD et al. 2009), dados do Global Forest Watch mostram que, só em 2019, uma área de 3.8 milhões de hectares (aproximadamente o tamanho da Suíça) foi abaixo, ou ardeu em chamas.

Além de dizimar a biodiversidade e estimular secas e picos de temperatura na própria região, o desmatamento afeta o regime de chuvas em outras localidades do Brasil (LOVEJOY e NOBRE, 2018) e eleva subitamente a emissões de gases, desequilibrando o clima em uma escala global. Constituindo-se, portanto, como um dos maiores problemas ambientais do mundo (FEARNSIDE, 2008). Isso sem falar no ataque à vida - já precária - de comunidades tradicionais e indígenas que há séculos habitam a Amazônia, guardiãs de culturas e saberes tácitos vitais para responder às perguntas que ainda faremos à floresta.

Mesmo que esse processo esteja atrelado fortemente ao avanço de atividades produtivas, a economia regional se caracteriza mais pelos efeitos nefastos dessa concepção predatória de progresso do que por conquistas socioeconômicas. Embora ocupe $60 \%$ do território brasileiro, a Amazônia só contribui com cerca de $8 \%$ do produto interno bruto (PIB) do país. Além disso, as 10 cidades mais pobres do Brasil estão na região e o número de pessoas em situação de extrema pobreza supera a média nacional em 7 dos seus 9 estados (IBGE, 2017). Até quando se observa as atividades predominantes, o que se constata é que, seja pela recorrência da ilegalidade ou pelo descumprimento de normas ambientais, os produtos e cadeias estão bastante suscetíveis a embargos em mercados internacionais (BALETTI, 2014).

A coexistência dessa miríade de problemas multicausais em uma região tão estratégica para o mundo permite enquadrar a Amazônia como um "grand challenge" da contemporaneidade. Assim como as mudanças climáticas, a extrema pobreza, o envelhecimento populacional e outros desafios da atualidade, a região possui um conjunto de obstáculos complexos, envolvendo diferentes sistemas e atores, cujo 


\section{소요요}

equacionamento pode sanar problemas sociais importantes a nível global. O que reforça a necessidade de conhecer melhor alguns desafios da região e o aporte de lentes teóricas que ajudem a enfrentá-los de modo mais efetivo, tal como se propõe nesse trabalho.

\section{Procedimentos metodológicos}

A fim de conhecer melhor a produção acadêmica sobre meta-organizações, em especial, aquela referente à atuação desses arranjos em prol da sustentabilidade, realizou-se uma revisão sistemática das publicações indexadas no Portal de Periódicos da Capes, abrangendo um período de 15 anos, desde a emergência do conceito, em 2005, até o ano 2020. Seguindo as diretrizes propostas por Tranfield, Denyer e Smart (2003), elaborou-se inicialmente o protocolo de pesquisa, no qual se definiu parâmetros importantes, como a busca apenas por publicações do tipo "artigos" e por periódicos avaliados por pares, bem como os termos utilizados como filtro de pesquisa: "meta-organizations"; "meta-organisations" e "meta-organizações".

Na sequência, procedeu-se a busca e a extração dos trabalhos, constituindo um corpo de 19 artigos, organizados em uma planilha eletrônica de acordo com: título, autoria, periódico, ano de publicação, resumo, palavras-chave, objetivo, abordagem de pesquisa, aspectos ligados a sustentabilidade e principais contribuições. O que possibilitou, por fim, a análise das implicações relacionadas a sustentabilidade presentes em cada um deles.

Já no que tange o mapeamento dos desafios da Amazônia, recorreu-se à múltiplas fontes de informação, começando pela leitura de artigos e livros reconhecidos nesse campo de estudos (CARDOSO e MÜLLER, 2008; BOLLE, CASTRO e VEJMELKA, 2010; COSTA, 2019), e por relatórios produzidos pelos governos locais e por outras entidades estabelecidas nesse território. Em seguida, participou-se de distintos eventos (on line), como: o Seminário Construindo Diálogos sobre Governança Florestal: Conservação, Manejo Sustentável e Restauração de Paisagens - que reuniu de pesquisadores de referência a indígenas e líderes comunitários; a série Diálogos Amazônicos - realizada pela Escola de Economia de São Paulo da Fundação Getúlio Vargas (FGV EESP), com a participação de gestores de grandes empresas, políticos e representantes do terceiro setor; e o Seminário Amazônia: desmatamento, crime organizado e corrupção organizado pelo Ministério Público Federal (MPF). Por reconhecer a dimensão internacional da região, acompanhou-se também alguns debates promovidos por organizações estrangeiras, como os seminários (on line) "Reflexiones políticas y jurídicas sobre la protección del medio ambiente y las políticas de desarrollo en la Amazonia", organizado pelo Centro de Estudos Brasileiros (CEB) da Universidade de Salamanca (USAL), da Espanha; e o painel "Making Sustainable Development a Reality in the Amazon", pela Americas Society - Council of the Americas, sediada nos Estados Unidos.

Por mais que esse mapeamento não tenha aspirado por um censo ou por generalizações de qualquer natureza, mas somente pela contextualização da agenda de pesquisa proposta, utilizou-se ainda a técnica bola de neve para abordar profissionais reconhecidos, em diferentes áreas de atuação, pelo engajamento com problemas amazônicos, conduzindo assim 06 (seis) entrevistas abertas (BAUER e GASKELL, 2002). Em consonância com as medidas de distanciamento necessárias, esses relatos foram obtidos por videoconferência, entre maio de 2020 e março de 2021, e duraram em média 60 minutos.

Ao combinar diferentes fontes, a pesquisa atenuou vieses relacionados à origem de alguns dados secundários, bem como aos interesses, focos de atuação e perfis dos entrevistados, gerando um corpus textual plural, que, após organizado, foi analisado de acordo com as três etapas a seguir: i) identificação dos desafios (tensões, obstáculos e problemas) relacionados ao contexto amazônico; ii) agrupamento e 
descrição dos desafios elencados com maior recorrência; e, iii) síntese desses desafios de acordo com algumas causas e desdobramentos a eles atribuídos. Além de originar o mapeamento desejado, esse processo possibilitou um entendimento mais profundo dos desafios e o conhecimento de organizações engajadas no enfrentamento dos mesmos, observando inclusive que algumas delas possuem um design meta-organizacional. O que, além de realçar o valor deste trabalho, permitiu apontar possíveis casos de estudo no decorrer da agenda de pesquisa. Afinal, como defende Malets (2009, p.5), "as meta-organizações são melhores descritas como fonte de muitas ideias interessantes que precisam ser empiricamente testadas".

\section{Resultados}

\subsection{Meta-organizações e sustentabilidade - apontamentos a partir da literatura}

Por meio da revisão da literatura empreendida, verificou-se que primeira publicação relacionando metaorganizações e sustentabilidade ocorreu apenas no ano 2012, cerca de 7 (sete) anos após a proposição do conceito, e ainda, que o maior volume de artigos data do ano 2018. Logo, observa-se que a temática ainda é bastante emergente, e demanda um conjunto considerável de esforços teóricos-analíticos para se estabelecer como uma linha de pesquisa amplamente reconhecida. O que parece extremamente factível, sobretudo se considerarmos que os debates sobre o tema têm sido acolhidos por periódicos de renome internacional, e que há uma heterogeneidade significativa entre os autores desses estudos. Com exceção de alguns pesquisadores de maior destaque, como Heloise Berkowitz e Sanne Bor, o que mais se percebe é uma forte diversidade, seja de universidades e centros de pesquisa, como de países e áreas de atuação. $O$ que inclusive ajuda a entender a pluralidade de casos enfocados por esses autores.

Ao abranger um leque variados de experiências, desde organizações de assistência à saúde (SANNE e BOR, 2018) e arranjos engajados com as mudanças climáticas em diferentes países (CHAUDHURY et al., 2016), às associações voltadas para a bioeconomia dos oceanos (BERKOWITZ et al., 2020) e aquelas formadas no âmbito de cadeia específicas (BERKOWITZ et al., 2017; CARMAGNAC e CARBONE, 2018), esses estudos têm demostrado que meta-organizações surgem por objetivos diferentes e em contextos variados, reforçando a necessidade de entendê-las mais a fundo.

Contudo, apesar dessa diversidade, percebe-se que, conforme assinalado por outros estudos (VIFFEL e THEDVALL, 2012), há um foco predominante no pilar ambiental da sustentabilidade, bem como uma convergência sobre os fatores que auxiliam meta-organizações a atuarem nessa agenda. Daí porque um estudo de destaque é de Berkowitz (2018), no qual a autora propõe um framework relacionando as capacidades organizacionais características de inovações sustentáveis (antecipação, resiliência, reflexividade, responsabilidade, inclusão e accountability) com os aspectos centrais de meta-organizações. Assim, pesquisas futuras podem averiguar como o aprendizado coletivo, a produção de informação e a flexibilidade, entre outros fatores, podem facilitar o surgimento e a difusão de inovações sustentáveis, abordando, a um só tempo, os três pilares da sustentabilidade.

Além disso, percebe-se também uma escassez de estudos sobre a atuação desses arranjos no Sul global. Embora os países dessa região tenham carências históricas em todas as facetas da sustentabilidade, poucos estudos têm se voltando para essas realidades, o que representa uma oportunidade ímpar para estudiosos interessados em desenvolver essa linha de pesquisa em nações como o Brasil. Entre os poucos 
estudos focados em contextos diferentes do anglo-saxônico, estão o de Chaudhury et al., (2016), que permitiu ver, por exemplo, como características institucionais de três países distintos (Nepal, Paquistão e Gana) implicam em assimetrias estruturais entre meta-organizações engajadas com questões climáticas, e o de Valente e Oliver (2018), que mostrou como esses arranjos são fundamentais para o combate à pobreza na África. Ambos com contribuições importantes para os debates realizados em torno dessas configurações organizacionais particulares, reforçando assim a demanda por pesquisas atentas às particularidades sócioculturais dos ambientes de atuação desses arranjos.

Em relação às contribuições fornecidas pelos estudos à gestão dos arranjos meta-organizacionais, percebese que ainda há uma forte lacuna de estudos dedicados à construção e proposição de diretrizes práticas às meta-organizações. Ao analisar a dinâmica desses arranjos, estudos têm apontado como metaorganizações podem ser protagonistas na criação de mercados sustentáveis (PEIXOTO e ARMI, 2019), na promoção da equidade de gênero (KARLBERG e JACOBSSON, 2015) e no aumento do capital intelectual em espaços coletivos (VALE, RIBEIRO e BRANCO, 2016). Contudo, é preciso que estratégias organizacionais sejam discutidas de modo mais pragmático, auxiliando esses arranjos a alcançarem seus objetivos, dentre os quais, a própria transição para a sustentabilidade.

Já no que toca as sugestões para futuros estudos, nota-se, por um lado, apontamentos de cunho metodológico, como a necessidade de combinar métodos (qualitativos e quantitativos) e de realizar pesquisas longitudinais; de outro, a própria demanda por pesquisas que aprofundem o debate sobre a importância dessas formas organizacionais para a sustentabilidade. Não à toa, até mesmo nos estudos que sugerem redirecionar o foco dos desafios globais para os problemas de utilidade pública, como é o caso de Lauren et al., (2019), percebe-se uma preocupação com diversos aspectos ligados a sustentabilidade.

Em suma, constata-se que, apesar de recente, o estudo de meta-organizações com foco em aspectos e problemas ligados a sustentabilidade possui um potencial significativo de desenvolvimento. Do contrário, periódicos de renome não acolheriam os debates sobre o tema, e seria difícil imaginar uma pluralidade de pesquisadores tão significativa em torno dos mesmos. Por meio de vários casos, em distintos setores, países e contextos, acadêmicos têm mostrado o papel desses arranjos no enfrentamento de problemas complexos, reforçando o papel de tais formas organizacionais na contemporaneidade. Contudo, para avançar no debate, é premente que se diversifique o lócus e de estudo e o foco, abordando países em desenvolvimento outros pilares da sustentabilidade, com destaque para o pilar social. Outro ponto de igual relevância é direcionar esforços na construção de proposições práticas, que norteiem a construção e a gestão desses esforços, amparando, portanto, a própria efetividade desses espaços coletivos de tomara de decisão e governança

Quadro 01: Síntese da revisão de literatura de acordo com autoria, ano, periódico, caso(s) abordado(s) e implicações para a sustentabilidade 


\begin{tabular}{|c|c|c|c|c|}
\hline & Autoria & Periódico & Caso(s) & Implicações para a sustentabilidade \\
\hline 1 & $\begin{array}{l}\text { Viffel e Thedvall } \\
(2012)\end{array}$ & $\begin{array}{l}\text { Sustaintability: } \\
\text { Science, Practice } \\
\text { and Policy }\end{array}$ & Fair-trade & $\begin{array}{l}\text { Fatores relacionados à disseminação e ao } \\
\text { fortalecimento de ideias e conteúdos sustentáveis } \\
\text { no campo dos alimentos orgânicos. }\end{array}$ \\
\hline 2 & $\begin{array}{l}\text { Karlberg e } \\
\text { Jacobsson (2015) }\end{array}$ & Voluntas & $\begin{array}{l}\text { Movimentos } \\
\text { sociais }\end{array}$ & $\begin{array}{l}\text { As consequências de processos de } \\
\text { internacionalização viabilizados por meio de } \\
\text { estruturas meta-organizacionais no campo dos } \\
\text { movimentos sociais. }\end{array}$ \\
\hline 3 & $\begin{array}{l}\text { Chaudhury, } \\
\text { Ventresca, } \\
\text { Thornton, } \\
\text { Helfgott, Sova, et } \\
\text { al. (2016) }\end{array}$ & $\begin{array}{l}\text { Global } \\
\text { Environmental } \\
\text { Change }\end{array}$ & Agenda do clima & $\begin{array}{l}\text { Estruturas de meta-organizações envolvidas com } \\
\text { as mudanças climáticas, a necessidade de } \\
\text { legitimidade e a importância dada ao tema } \\
\text { diferentes países }\end{array}$ \\
\hline 4 & $\begin{array}{l}\text { Berkowitz e } \\
\text { Dumez (2016) }\end{array}$ & $\begin{array}{l}\text { European } \\
\text { Management } \\
\text { Review }\end{array}$ & (não se aplica) & $\begin{array}{l}\text { É necessário desenvolver novas formas de } \\
\text { teorização da ação coletiva, adotando novas } \\
\text { metodologias, teorias e abordagens originais }\end{array}$ \\
\hline 5 & $\begin{array}{l}\text { Vale, Branco } \\
\text { e Ribeiro } \\
(2016)\end{array}$ & $\begin{array}{l}\text { Journal of } \\
\text { Intellectual Capital }\end{array}$ & Portuária & $\begin{array}{l}\text { Interfaces entre o capital intelectual dos membros } \\
\text { e das meta-organizações, mostrando como ambos } \\
\text { são criados e deteriorados ao longo do tempo. }\end{array}$ \\
\hline 6 & \begin{tabular}{l|} 
Radnejad, \\
Vredenburg e \\
Woiceshyn (2017)
\end{tabular} & Technovation & Petróleo e gás & $\begin{array}{l}\text { Influência de forças institucionais na adoção da } \\
\text { inovação aberta no setor estudado. }\end{array}$ \\
\hline 7 & $\begin{array}{l}\text { Berkowitz, } \\
\text { Bucheli e Dumez } \\
\text { (2017) }\end{array}$ & $\begin{array}{l}\text { Journal of Business } \\
\text { Ethics }\end{array}$ & Petróleo e gás & $\begin{array}{l}\text { Tipologia de meta-organizações com base no caso } \\
\text { de programas de responsabilidade social } \\
\text { existentes no setor de petróleo e gás. }\end{array}$ \\
\hline 8 & Berkowitz (2018) & $\begin{array}{l}\text { Journal of Cleaner } \\
\text { Production }\end{array}$ & (não se aplica) & $\begin{array}{l}\text { Relacionamento entre capacidades de inovações } \\
\text { sustentáveis e atributos de meta-organizações. }\end{array}$ \\
\hline 9 & $\begin{array}{l}\text { Berkowitz e Bor } \\
(2018)\end{array}$ & $\begin{array}{l}\text { Journal of } \\
\text { Management } \\
\text { Inquiry }\end{array}$ & (não se aplica) & $\begin{array}{l}\text { O papel de meta-organizações na defesa de } \\
\text { interesses e objetivos coletivos. }\end{array}$ \\
\hline 10 & $\begin{array}{l}\text { Cropper e Bor } \\
(2018)\end{array}$ & $\begin{array}{l}\text { Administrative } \\
\text { Sciences }\end{array}$ & Saúde & $\begin{array}{l}\text { O caráter e as circunstâncias de parcerias } \\
\text { envolvendo meta-organizações. }\end{array}$ \\
\hline 11 & $\begin{array}{l}\text { Carmagnac e } \\
\text { Carbone }(2018)\end{array}$ & $\begin{array}{l}\text { Supplv Chain } \\
\text { Forum: An } \\
\text { International } \\
\text { Journal }\end{array}$ & $\begin{array}{l}\text { Cadeias de valor } \\
\text { globais }\end{array}$ & $\begin{array}{l}\text { Meta-organizações atuantes em cadeias de } \\
\text { suprimento conseguem modificar o ambiente de } \\
\text { atuação de seus membros, criando um espaço de } \\
\text { ação coletiva e cooperação. }\end{array}$ \\
\hline 12 & $\begin{array}{l}\text { Fumasoli, } \\
\text { Stensaker e } \\
\text { Vukasovic (2018) }\end{array}$ & $\begin{array}{l}\text { European } \\
\text { Educational } \\
\text { Research Journal }\end{array}$ & $\begin{array}{l}\text { Educação } \\
\text { superior }\end{array}$ & $\begin{array}{l}\text { A importância de meta-organizações formas por } \\
\text { atores transnacionais na governança do } \\
\text { conhecimento na Europa, apelando pelo aporte de } \\
\text { outras lentes teóricas no estudo do tema. }\end{array}$ \\
\hline 13 & $\begin{array}{l}\text { Valente e Oliver } \\
(2018)\end{array}$ & $\begin{array}{l}\text { Organization } \\
\text { Science }\end{array}$ & (variados) & $\begin{array}{l}\text { Eficiência de meta-organizações quando os } \\
\text { participantes exibem uma abertura para formas } \\
\text { inovadoras de colaboração e quando conseguem } \\
\text { transformar recursos em prol de objetivos } \\
\text { sistêmicos }\end{array}$ \\
\hline 14 & $\begin{array}{l}\text { Corazza, Cisi e } \\
\text { Dumay (2019) }\end{array}$ & $\begin{array}{l}\text { Knowledge } \\
\text { Management } \\
\text { Research \& } \\
\text { Practice }\end{array}$ & $\begin{array}{l}\text { Redes de } \\
\text { negócios }\end{array}$ & $\begin{array}{l}\text { O papel da aprendizagem colaborativa ao longo de } \\
\text { três estágios progressivos: proteção de bens } \\
\text { comuns, administração de bens comuns e } \\
\text { governança de bens comuns. }\end{array}$ \\
\hline 15 & $\begin{array}{l}\text { Berkowitz e } \\
\text { Souchau (2019) }\end{array}$ & $\begin{array}{l}\text { Journal of Business } \\
\text { Ethics }\end{array}$ & $\begin{array}{l}\text { Financiamento } \\
\text { coletivo }\end{array}$ & $\begin{array}{l}\text { Contribuições de meta-organizações formadas por } \\
\text { múltiplos stakeholders na qovernança por meio de } \\
\text { ações coletivas e de processos de participação } \\
\text { social. }\end{array}$ \\
\hline 16 & $\begin{array}{l}\text { Peixoto e Armi } \\
(2019)\end{array}$ & $\begin{array}{l}\text { Journal of Cleaner } \\
\text { Production }\end{array}$ & Biocombustíveis & $\begin{array}{l}\text { Objetivos políticos conflitantes dificultam a criação } \\
\text { de mercados voltados para a sustentabilidade. }\end{array}$ \\
\hline 17 & $\begin{array}{l}\text { Laurent, } \\
\text { Garaudel, } \\
\text { Schmidt e Eynaud } \\
(2020)\end{array}$ & Voluntas & $\begin{array}{l}\text { Organização } \\
\text { social }\end{array}$ & $\begin{array}{l}\text { Relevância da representatividade das partes } \\
\text { interessadas não somente na governança, como }\end{array}$ \\
\hline
\end{tabular}




\begin{tabular}{|l|l|l|l|l|}
\hline & & & $\begin{array}{l}\text { na legitimidade e no potencial a ação de arranjos } \\
\text { meta-organizacionais. }\end{array}$ \\
\hline 18 & $\begin{array}{l}\text { Berkowitz, } \\
\text { Crowder e Brooks } \\
(2020)\end{array}$ & Marine Policy & $\begin{array}{l}\text { Bioeconomia dos } \\
\text { oceanos }\end{array}$ & $\begin{array}{l}\text { Dimensões ideais típicas e condições de contorno } \\
\text { para um modelo de meta-organizações voltadas } \\
\text { para a governança dos oceanos. }\end{array}$ \\
\hline 19 & $\begin{array}{l}\text { Zyzak e Jacobsen } \\
(2020)\end{array}$ & $\begin{array}{l}\text { Public Management } \\
\text { Review }\end{array}$ & $\begin{array}{l}\text { Conselhos } \\
\text { regional }\end{array}$ & $\begin{array}{l}\text { Capacidades de gestão necessárias para a } \\
\text { articulação de redes de gestores. }\end{array}$ \\
\hline
\end{tabular}

Fonte: Dados da pesquisa.

\subsection{Alguns dos inúmeros desafios amazônicos}

Quando se enxerga a Amazônia para além dos seus estereótipos, se dá conta da sua realidade plural, e que comporta múltiplas "Amazônias" (MENDES, 2006). Logo, tem-se total ciência que os desafios mapeados, além de não constituírem um gabarito, também podem ser descabidos em determinados contextos e localidades desse território tão amplo e diverso. De todo modo, é válido sinalizar que praticamente todos os 22 desafios registrados ecoam, de alguma maneira, na literatura, nos debates, documentos e relatos analisados, o que denota a pertinência de cada um deles e do próprio caminho metodológico percorrido. De dificuldades estruturais e logísticas amplamente conhecidas, àqueles entraves aflorados ou reforçados pela pandemia, parece haver uma concordância em torno desses obstáculos para o desenvolvimento sustentável da Amazônia. O que, inclusive, reforça a demanda por mecanismos organizacionais que forjem estratégias de ação mais robustas capazes de conduzir esse processo - os problemas, ao que parece, já se sabem.

No entanto, pela impossibilidade de dissertar longamente sobre cada um deles no escopo deste artigo, escoltou-se em uma leitura atenta dos dados para fazer um recorte das demandas elencadas com mais recorrência, chegando enfim a 4 desafios tidos como "urgentes", descritos de acordo com algumas causas e desdobramentos a eles atribuídos no decorrer dos relatos.

Quadro 02: Síntese dos desafios abordados na agenda de pesquisa

\begin{tabular}{|l|l|l|}
\hline \multicolumn{1}{|c|}{ Desafios } & \multicolumn{1}{c|}{ Causas } & \multicolumn{1}{c|}{ Desdobramentos } \\
\hline $\begin{array}{l}\text { Acabar com o } \\
\text { desmatamento }\end{array}$ & $\begin{array}{l}\text { Atividades ilegais em terras } \\
\text { públicas e unidades de } \\
\text { conservação; Falta de políticas } \\
\text { ambientais efetivas; } \\
\text { Enfraquecimento dos órgãos } \\
\text { responsáveis pelo controle e } \\
\text { fiscalização; Desarticulação dos } \\
\text { atores locais; Modelo de } \\
\text { desenvolvimento calcado na } \\
\text { degradação do meio ambiente. }\end{array}$ & $\begin{array}{l}\text { Emissão crescente de gases de efeito } \\
\text { estufa; Alteração dos ciclos de chuva na } \\
\text { América do Sul e dos padrões climáticos a } \\
\text { nível global; Perda de biodiversidade; } \\
\text { Prejuízo para cadeias produtivas do } \\
\text { agronegócio e, tão logo, no PIB; Aumento } \\
\text { da poluição do ar; Riscos à saúde pública; } \\
\text { Danos à imagem dos produtos brasileiros } \\
\text { e do país no exterior. }\end{array}$ \\
\hline $\begin{array}{l}\text { Assegurar os direitos de } \\
\text { povos } \\
\text { indígenas/comunidades } \\
\text { tradicionais }\end{array}$ & $\begin{array}{l}\text { Desrespeito aos direitos culturais e } \\
\text { modo de vida dos povos indígenas } \\
\text { e comunidades tradicionais; } \\
\text { Descaso com a demarcação de } \\
\text { terras indígenas; Atividades ilegais } \\
\text { em reservas indígenas; Falta de } \\
\text { serviços básicos, saúde e } \\
\text { educação. }\end{array}$ & $\begin{array}{l}\text { Valorização do conhecimento de povos } \\
\text { indígenas e comunidades tradicionais; } \\
\text { Permanência de jovens em suas } \\
\text { comunidades; Repasse dos saberes } \\
\text { seculares sobre os insumos da floresta. }\end{array}$ \\
\hline $\begin{array}{l}\text { Garantir educação e } \\
\text { empregos de qualidade }\end{array}$ & $\begin{array}{l}\text { Instalações impróprias; } \\
\text { Infraestrutura de acesso precária; } \\
\text { Baixo índices de aprendizagem; } \\
\text { Casos de trabalho precário. }\end{array}$ & $\begin{array}{l}\text { Melhoria da qualificação profissional; } \\
\text { Fortalecimento do capital social; } \\
\text { Diminuição da informalidade; Consciência } \\
\text { política; Formação de empreendedores }\end{array}$ \\
& \multicolumn{2}{|l}{} \\
\hline
\end{tabular}




\begin{tabular}{|l|l|l|}
\hline & $\begin{array}{l}\text { Migrações de jovens para os } \\
\text { grandes centros. }\end{array}$ & $\begin{array}{l}\text { atentos às oportunidades da floresta em } \\
\text { pé. }\end{array}$ \\
\hline $\begin{array}{l}\text { Fomentar cadeias e } \\
\text { negócios sustentáveis }\end{array}$ & $\begin{array}{l}\text { Conflito de lógicas (produzir x } \\
\text { preservar); Falta de consciência } \\
\text { sobre o manejo sustentável; Falta } \\
\text { de investimentos em educação, } \\
\text { ciência e tecnologia. Assimetrias de } \\
\text { poder ao longo das cadeias; Falta } \\
\text { de articulação e coesão em torno } \\
\text { de causas sustentáveis. }\end{array}$ & $\begin{array}{l}\text { Geração de renda, conservação e } \\
\text { regeneração ambiental; Valorização de } \\
\text { conhecimentos tradicionais; Potência } \\
\text { global no mercado da bioeconomia; } \\
\text { Aumento da competividade do país. } \\
\text { Inovações em produtos e modelos de } \\
\text { negócios; Legitimidade pela } \\
\text { sustentabilidade. }\end{array}$ \\
\hline
\end{tabular}

Fonte: Dados da pesquisa.

Ainda que por meio de uma visão esquemática, a apreensão desses desafios revela a complexidade inerente a cada um deles e um conjunto de interfaces entre determinadas causas e desdobramentos trazidos à tona. Quando se diz que "estamos queimando a Monalisa" (E3), por exemplo, se refere à correlação entre o desmatamento e a da falta de visão para os possíveis ganhos de uma economia da floresta em pé. Indo além, quando se aborda um desdobramento positivo de melhorias na educação, como o fortalecimento do capital social, fala-se de algo fundamental para atenuar a falta de coesão, problema que subjaz o fortalecimento das cadeias e negócios sustentáveis. Em suma, há desafios em cascata, compostos por dificuldades específicas, que, não raro, se combinam e geram uma trama de relações ainda mais complexas que cada desafio isolado, e cujo a compreensão passa, inevitavelmente, por estudos específicos. De óbvio, só o que expôs um dos entrevistados: "a Amazônia não é para iniciantes!" (E1).

\subsection{Meta-organizações e Amazônia - uma agenda de pesquisa}

Com base na revisão de literatura realizada e no mapeamento de alguns desafios "urgentes" da Amazônia legal, delineou-se um conjunto diverso de propostas de pesquisa, abrangendo não somente questões relativas à contribuição de meta-organizações para a sustentabilidade da região, como também uma possível atuação em sentido inverso, e ainda, aspectos ligados à dinâmica interna desses arranjos e aos relacionamentos interorganizacionais com outras organizações, inclusive de cunho meta-organizacional.

\section{Quem são? Onde estão? 0 que fazem? - a necessidade de um mapeamento}

Considerando a falta de estudos utilizando a noção de meta-organizações para analisar tais arranjos na Amazônia, há, sem dúvida, uma ampla possibilidade de caminhos que são muito importantes. Portanto, é premente que se realizem mapeamentos e descrições dessas experiências, capazes de apresentá-las à comunidade acadêmica sob as lentes desse conceito e de suas respectivas particularidades. Em conjunto, esses estudos proverão contribuições fundamentais para o avanço dessa agenda de pesquisa, sobretudo no que toca a criação de um entendimento inicial que permita comparar esses arranjos, tanto entre si, quanto com outras organizações "tradicionais" existentes em seus respectivos campos de atuação. Sem esse corpo de conhecimento minimamente constituído, a tendência é que as tentativas de compreender as metaorganizações presentes no contexto amazônico implique esforços mais árduos, demorados e frágeis, acabando por inviabilizar muitas pesquisas necessárias sobre essas experiências. 


\section{As contribuições de meta-organizações para a sustentabilidade na Amazônia}

Atendendo a demanda por estudos que consigam explicar como essas formas têm auxiliado a transição para a sustentabilidade (BERKOWITZ e BOR, 2018), outro caminho de pesquisa bastante oportuno reside nas análises sobre os processos que conduzem a impactos sociais, ambientais e econômicos positivos por parte das metaorganizações, averiguando se, e como, elas têm promovido e fortalecido uma agenda sustentável no contexto amazônico. Conhecendo o papel dos povos indígenas para a preservação da floresta, e sabendo que um desafio em voga é: Assegurar os direitos de povos indígenas/comunidades tradicionais, pesquisas podem abordar, por exemplo, casos como o da Coordenação das Organizações Indígenas da Bacia Amazônica (COICA) e da Coordenação das Organizações Indígenas da Amazônia Brasileira (COIAB).

A Coordenação das Organizações Indígenas da Bacia Amazônica (COICA) é uma organização indígena internacional que orienta seus esforços para a promoção, proteção e segurança dos povos e territórios indígenas, partir de uma estrutura organizacional complexa, composta por associações indígenas de diversos países da pan-amazônia, dentre eles o Brasil. Já a Coordenação das Organizações Indígenas da Amazônia Brasileira (COIAB) tem abrangência regional. Criada em 1989, com a missão de representar os 180 povos indígenas distintos estabelecidos na Amazônia brasileira, a organização é composta por 64 entidades, oriundos de nove estados (Amazonas, Acre, Amapá, Maranhão, Mato Grosso, Pará, Rondônia, Roraima e Tocantins), representando cerca de 430.000 de pessoas. O que representa $60 \%$ da população indígena do país e lhe assegura o posto de maior organização indígena do Brasil. Por meio de atividades orquestradas coletivamente, a organização tem conseguido denunciar projetos de lei que ferem os interesses indígenas, formar lideranças políticas, lutar pela demarcação das terras e estabelecer diálogos com grandes empreendimentos.

Por meio desses casos, pesquisas podem diversificar os debates realizados nesse campo, em especial, no que toca a demanda por estudos sobre o pilar social da sustentabilidade, inovando ainda, ao trazer metaorganizações de base comunitária, formadas por povos tradicionais da floresta. Outra possibilidade advinda da existência de duas meta-organizações distintas que compartilham a mesma agenda é a realização de estudos comparativos, que elucidem diferenças e similitudes entre os arranjos (BERKOWITZ e DUMEZ, 2016), sobretudo no que concerne a influência do contexto nacional sob essas formas alternativas de organização.

Em conjunto, esses estudos também podem reverberar positivamente no campo da prática, criando referências para o desenho e para a gestão de novas experiências, seja por parte de outros coletivos indígenas ou por grupos que compartilham lutas similares, como quilombolas e ribeirinhos, por exemplo. Em favor dessa abordagem, há toda uma tradição de pesquisas sobre organizações indígenas em diferentes campos do saber, com destaque para o trabalho desenvolvido pelas próprias universidades da região amazônica. Embora não se utilizem da noção de meta-organizações, muitos grupos de pesquisa têm lastro na análise desses arranjos, oferecendo frequentemente contribuições para a compreensão e articulação dos mesmos. O que reafirma o caráter interdisciplinar das pesquisas propostas, afinal, trata-se de organizações complexas, trabalhando com problemas complexos, e em contextos complexos.

Outro desafio alinhado à essa abordagem é de: Fomentar cadeias e negócios sustentáveis. Considerando o potencial de meta-organizações no estabelecimento de padrões e certificações em distintos setores, pesquisas podem verificar como determinados programas têm conseguido alavancar o trabalho de comunidades, empreendimentos e cadeias produtivas específicas na Amazônia, ou ainda, na própria formação de um campo organizacional em torno dos "negócios da floresta". Uma experiência interessante tem sido a do Selo Origens, iniciativa meta organizacional que reúne organizações do terceiro setor, 
comunidades e grandes empresas, com foco na produção, distribuição e comercialização de produtos da biodiversidade.

Desde 2016, a iniciativa atua em áreas prioritárias de conservação, com garantia de origem, transparência, rastreabilidade da cadeia produtiva, promovendo o comércio justo e ético por meio de elos com quem produz e com quem compra, ou seja, a partir de conexões que geram impactos positivos para as populações e seus territórios. Apesar dos entraves característicos da região, o programa possui um portfólio diversificado que abrange desde produtos do extrativismo (óleos vegetais, resinas, sementes, extratos) e do agroextrativismo (mel, pimenta, farinha, chocolate), até itens provenientes da cultura material e imaterial do território (artesanatos indígenas, dentre outros).

A capacidade de articulação dessa iniciativa conduz a diferentes questões, como: em que medida esse arranjo tem sido mais efetivo que outras estratégias de fomento à bioeconomia realizadas por parte do poder público ou da iniciativa privada? É válido, contudo, que essa compreensão passe por estudos com recorte longitudinal, contemplando os efeitos de médio e longo prazo produzidos por tais arranjos. Seja entendo como eles têm conseguido moldar os seus próprios ambientes e reduzido incertezas (BERKOWITZ e BOR, 2018), ou então, conhecendo melhor as dificuldades presentes em suas trajetórias, tais pesquisas podem calcar novas estratégias de desenvolvimento para essas cadeias tão fundamentais à existência da floresta. Afinal, sabe-se que formas organizacionais calcadas na cooperação, como redes, por exemplo, também possuem limites (SOUSA, VASCONCELLOS e VASCONCELLOS, 2012).

\section{As dinâmicas internas e externas de meta-organizações}

Em face da necessidade de entender melhor como a estrutura e a diversidade de membros afeta a dinâmica organizacional desses arranjos (BERKOWITZ e DUMEZ, 2016), uma via de investigação frutífera pode ser aquela focada nos processos e práticas organizacionais que as alicerçam, abordando assim a dinâmica organizacional dessas coleções de organização. Seja por meio de abordagens isoladas ou comparativas, esses estudos poderão descortinar tanto as práticas gerenciais típicas dessas organizações, como também uma série de questões relacionadas aos atores, papéis, responsabilidades e desafios dessas iniciativas. $O$ que pode possibilitar uma visão mais clara desses arranjos e do manejo de suas típicas incertezas normalmente desdobradas pela forte dependência de seus membros ou por relações de competição estabelecidas entre eles e a organização em si (AHRNE e BRUNSSON, 2005). Por isso, um tópico instigante reside nas configurações de poder, sobretudo naqueles arranjos compostos por diferentes stakeholders. Ao abordá-las, pode-se compreender "como meta-organizações conseguem ser inclusivas e fomentar a diversidade de experiências e propostas entre seus membros?", permitindo que vários atores influenciem suas estratégias institucionais.

Em suma, é preciso averiguar em que medida essas formas organizacionais apontam para um contexto de relações democráticas, que favorecem a produção coletiva de soluções, ou um contexto desbalanceado, no qual se sobressaem os interesses e vozes de determinados atores. Em meta-organizações de grande porte, práticas dedicadas a esse propósito devem ser cada vez mais recorrentes, o que faz sugerimos a Coalizão Brasil Clima, Florestas e Agricultura como um possível caso de estudo. Trata-se de um movimento multisetorial, composto por mais de 300 entidades de destaque no agronegócio brasileiro, dentre elas, as principais organizações civis da área de meio ambiente e clima, representantes do meio acadêmico, associações setoriais e companhias líderes nas áreas de madeira, cosméticos, siderurgia, papel e celulose, entre outras. Lançada em 2014, a organização é pautada em um documento com 17 propostas voltadas à redução das emissões de GEE e à economia de baixo carbono, elaboradas com base em estudos científicos, conhecimento prático e tecnologias disponíveis no país: o fim do desmatamento e da exploração ilegal de madeira, a recuperação de áreas degradadas, o ordenamento fundiário, a proteção social de comunidades, 
bem como o estímulo à produção competitiva e sustentável de alimentos, produtos florestais e bioenergia. O que, por certo, demanda a capacidade de dialogar e de promover o diálogo entre forças comumente distantes.

Em uma cascata de oportunidades e dúvidas salientes, se concebermos que esses diálogos, não raro, originam ou são originados a partir de relações de cooperação, há que se abordar "como se desenvolvem as relações de cooperação entre meta-organizações e outras organizações do setor público ou privado?". Por meio de análises comparativas com outros modelos organizacionais, estudos podem mostrar se, e como, aspectos de meta-organizações refletem na gestão e no relacionamento com parceiros externo. Algo fundamental para essas organizações entenderem os caminhos necessários para a formação de alianças efetivas, pois, apesar das virtudes que lhes são características, complementariedades e sinergias costumam ser passo inicial para resolver os desafios da Amazônia. A partir de diferentes recortes, pesquisas podem mostrar como características socioculturais e institucionais de contextos específicos condicionam as estruturas, processos e resultados desses arranjos. Afinal, sabe-se que condições e lógicas institucionais diferentes, dentro e entre as regiões, afetam significativamente a dinâmica de novas formas organizacionais (ZHAO e WRY, 2016).

Em face das problemáticas ligadas à educação presentes na Amazônia, o Fórum Estadual de Educação FEE estabelecido no Estado do Pará se revela como um caso interessante de estudo. Assim como os Conselhos Municipais analisados por Sousa, Fischer e Vasconcellos (2015), essa iniciativa tem intensificado a interlocução entre a sociedade civil e o setor público, contribuindo para a democratização do processo de concepção, implementação, acompanhamento e avaliação da política educacional do referido estado.

Originado na Conferência Nacional de Educação (CONAE - 2010), o FEE é composto por 27 entidades de diferentes searas, desde sindicatos patronais e entidades estudantis, às universidades e associações locais, que, juntas, têm feito reivindicações estratégicas para a melhoria da educação no Pará. Graças a isso, esse arranjo tem viabilizado inúmeras parcerias, convidando análises não somente sobre a dinâmica de metaorganizações multisetoriais, como também sobre as relações de cooperação com outros atores.

\section{A outra face das meta-organizações}

Apesar das evidências em torno das capacidades de meta-organizações, elas também podem produzir resultados indesejáveis e até avessos à sustentabilidade. Estudos no setor petrolífero evidenciam, por exemplo, situações em que essas tentativas de organização acabam, paradoxalmente, gerando desorganização (BERKOWITZ, 2015). Se lembrarmos que elas não surgem em um vácuo de relações de poder, e do próprio lastro de intervenções malfadadas na Amazônia, é vital abordar um possível "dark side", isto é, a outra face das meta-organizações. Ou seja, investigar se, e como, a articulação de esforços tem produzido e/ou reforçado problemas socioambientais na região, sobretudo o desmatamento. Se a capacidade de controlar o ambiente for mesmo comum a esses arranjos, servir à degradação os tornam tenebrosos.

Escoltados por evidências do uso político de burocracias (VIFFEL e THEDVALL, 2012), estudos podem enfocar, por exemplo, as federações ligadas ao agronegócio, pois sabe-se que o desmatamento da Amazônia está bastante atrelado ao modelo de exploração e uso da terra na região. Um possível caso é a Federação da Agricultura e Pecuária do Pará - FAEPA. Fundada em 1951, ela tem a missão de representar, organizar e fortalecer os produtores e sindicatos rurais, promovendo o agronegócio no estado - um dos estados que mais desmata na região. Com ações descentralizadas em 10 núcleos regionais e abrangendo 132 sindicatos rurais, a entidade possui representatividade em diversos fóruns privados e governamentais, tanto no âmbito estadual, como municipal, interferido na criação de políticas públicas focadas no setor. 
Nesse mesmo contexto, cumpre notar o valor de estudos que descortinem os aspectos simbólicos envoltos nesses arranjos. Seja pela legitimidade atribuída às decisões tomadas no âmbito de meta-organizações, ou pelo apelo internacional da Amazônia, não parece descabido pensar em um uso instrumental desses arranjos como mecanismos de legitimação e de melhoria de reputação. Em suma, é muito válido observar se, e como, a participação em meta-organizações têm servido a interesses pouco atrelados à suas respectivas missões institucionais.

Se considerarmos a multiplicidade de filiados à - já citada - Coalizão Brasil, tal organização instiga novamente um conjunto de estudos. Entre os seus membros, estão empresas como a JBS, cujo a história é marcada por episódios, digamos, "poucos sustentáveis" e até outras meta-organizações, como a Associação Brasileira do Agronegócio, que, ao representar os interesses mais amplos desse setor, acaba se vinculando às suas inúmeras externalidades negativas. Novas pesquisas podem sinalizar caminhos para que tais organizações operem realmente de modo sustentável, sem desviar das missões que propagam com tanto vigor, e podem propor por exemplo, mecanismos de controle que ajudem a evitar "bonecas" que não se encaixam nessas matrioskas, ou ainda, aspectos free rider, como falam Berkowitz et al., (2020).

\section{Considerações finais:}

Ao articular os esforços de múltiplos atores em diferentes processos de co-construção, meta-organizações podem desempenhar um papel estratégico para o desenvolvimento sustentável da Amazônia, contribuindo não somente para o enfrentamento de desafios locais, como também para o equacionamento de problemas globais - crise climática, produção de alimentos e preservação da biodiversidade, por exemplo. Atento para a escassez de conhecimento sobre a atuação desses arranjos na região, delineou-se uma agenda de pesquisa relacionando meta-organizações e desafios "urgentes" do contexto amazônico. Entre as oportunidades de pesquisa propostas, estão: o mapeamento dos arranjos que têm atuado, direta ou indiretamente, na região; a compreensão do papel desempenhado por tais formas no enfrentamento dos desafios amazônicos; o entendimento de suas dinâmicas internas e externas; e, a apreensão de problemas socioambientais possivelmente atrelados às mesmas.

Considerando o caráter emergente do conceito, a magnitude da região e a complexidade de seus desafios, não se espera que tais propostas desenhem um mapa de prioridades estáticas, mas sim, um convite efusivo às oportunidades de pesquisa existentes. "Essas organizações estão na floresta e é preciso entendê-las" essa é, sem dúvida, a mensagem central do trabalho. O que não impede, todavia, que se destaque o vigor das recomendações trazidas à tona, pois elas preparam o terreno para percursos teórico-analíticos bastante interessantes, e que prometem contribuir tanto para o alargamento dos debates sobre o tema, quanto para o enfrentamento dos problemas locais. Algo fundamental, pois ainda sabemos pouco sobre esses arranjos e seus desdobramentos (BERKOWITZ e DUMEZ, 2016), e precisamos, talvez como nunca na história, de estratégias organizacionais capazes de "superar a esfinge amazônica" e de construir uma nova história para o futuro da região (MENDES, 2006).

Se observarmos que renomados fóruns acadêmicos, como o EGOS, têm fomentado o debate desses arranjos, já se nota que tal agenda tem um forte apelo internacional. Contudo, é quando se considera a possibilidade dessas "matrioskas" serem de fato estratégicas para o enfrentamento de desafios da Amazônia, que fica claro a sua real importância à nível global. Afinal, se floresta só existe ficando em pé, e o mundo precisa dela para não colapsar, é premente que estudos organizacionais amparem a criação e o desenvolvimento dessas iniciativas. 


\section{Referências:}

AHRNE, G.; BRUNSSON, N. Organizations and meta-organizations. Scandinavian Journal of Management, 21(4), 429-449. 2005.

AHRNE, G.; BRUNSSON, N. Organization outside organizations: the significance of partial organization. Organization, 18(1), 83-104. 2011.

ARAGÓN, L.E. A dimensão internacional da Amazônia: um aporte para sua interpretação. Revista NERA, 21, n. 42, p.15-33. 2018.

BALETTI, B. Saving the Amazon? Sustainable soy and the new extractivism. Environment and Planning, volume 46, p.5-25. 2014.

BAUER, M. W.; GASKELL, G. Pesquisa qualitativa com texto, imagem e som. Tradução de Pedrinho A. Guareschi. Petrópolis: Vozes, 2002.

BERKOWITZ, H. Comment une idée abstraite peut devenir un dispositif de gestion : le cas du développement durable [1]. Annales des Mines - Gérer et comprendre, 121(3), 41-50. 2015.

BERKOWITZ, H. Meta-organizing firms' capabilities for sustainable innovation: a conceptual framework. Journal of Cleaner Production, 175, 420-430. 2018.

BERKOWITZ, H.; BOR, S. Why Meta-Organizations Matter: A Response to Lawton et. al., and Spillman. Journal of Management Inquiry, 27(2), 204-211. 2018.

BERKOWITZ, H.; DELACOUR, H. Sustainable Academia: Open, Engaged, and Slow Science. M@n@gement, 23(1), 1-3. 2020.

BERKOWITZ, H.; DUMEZ, H. La dynamique des dispositifs d'action collective entre firmes: Le cas des métaorganisations dans le secteur pétrolier. L'Année sociologique, vol. 65(2), 333-356. 2015.

BERKOWITZ, H.; DUMEZ, H. The Concept of Meta-Organization: Issues for Management Studies. European Management Review, 13(2), 149-156. 2016.

BERKOWITZ, H.; GROTHE-HAMMER, M. (forthcoming). From a clash of social orders to a loss of decidability in meta-organizations tackling grand challenges: The case of Japan leaving the International Whaling Commission. Research in the Sociology of Organizations.

BERKOWITZ, H.; SOUCHAUD, A. (Self-)regulation in the sharing economy: Governing through partial metaorganizing. Journal of Business Ethics, 159(4), 961-976. 2019.

BERKOWITZ, H, CROWDER, L. B.; BROOKS, C. M. Organizational perspectives on sustainable ocean governance: A multi-stakeholder, meta-organization model of collective action. Marine Policy, 118, 104026. 2020.

BOLLE, W.; CASTRO, E.; VEJMELKA, M. (Orgs.). Amazônia: região universal e teatro do mundo. São Paulo, Globo. 2010.

BROMLEY, D.W.; COCHRANE, J.A. Understanding the Global Commons. Working Papers 11890, Environmental and Natural Resources Policy Training Project. 1994.

CARDOSO, F.H.; MÜLLER, G. Amazônia: expansão do capitalismo (on line). Rio de Janeiro: Centro Edelsteons de Pesquisa Social. 168p. 2008. 
CARMAGNAC, L.; CARBONE, V. Making supply networks more sustainable 'together': the role of metaorganisations, Supply Chain Forum: An International Journal. 2018.

CASTRO, E. Políticas de estado e atores sociais na Amazônia contemporânea. In.: Bolle, W.; Castro, E.; Vejmelka, M. (Orgs.). Amazônia: região universal e teatro do mundo. São Paulo, Globo. 2010.

CHAUDHURY, A.S.; VENTRESCA, M.J.; THORNTON, T.F.; HELFGOTT, A.; SOVA, C., et al. "Emerging meta-organisations and adaptation to global climate change: Evidence from implementing adaptation in Nepal, Pakistan and Ghana." Global Environmental Change, 38, 243-257. 2016.

CORAZZA, L.; CISI, M.; DUMAY, J. "Formal networks: The influence of social learning in meta-organisations from commons protection to commons governance." Knowledge Management Research \& Practice. 2019.

COSTA, F. A. Brief Economic History of the Amazon (1720-1970). New castle upon Tyne: Cambridge Scholars Publishing, 2019.

CROPPER, S.; BOR, S. (Un)bounding the Meta-Organization: Co-Evolution and Compositional Dynamics of a Health Partnership. Adminstrative Sciences, 8 (3), 1-19. 2018.

FEARNSIDE, P.M. The roles and movements of actors in the deforestation of Brazilian Amazonia. Ecology Society. 13(1): 23. 2008.

FERRARO, F.; ETZION, D.; GEHMAN, J. "Tackling Grand Challenges Pragmatically: Robust Action Revisited." Organization Studies, 36 (3), 363-390. 2015.

FUMASOLI, T.; STENSAKER, B.; VUKASOVIC, M. Tackling the multi-actor and multi-level complexity of European governance of knowledge: Transnational actors in focus, European Educational Research Journal. 2017.

GEORGE, G.; HOWARD-GRENVILLE, J.; JOSHI, A.; TIHANYI, L. Understanding and Tackling Societal Grand Challenges through Management Research. Academy of Management Journal, 59 (6), 1880-1895. 2016.

IBGE - Instituto Brasileiro de Geografia e Estatística. Síntese de indicadores sociais: uma análise das condições de vida da população brasileira. Rio de Janeiro. 147p. 2017.

KARLBERG, E; JACOBSSON, K. A Meta-organizational Perspective on the Europeanization of Civil Society: The Case of the Swedish Women's Lobby. Voluntas: International Journal of Voluntary \& Nonprofit Organizations. Aug2015, Vol. 26 Issue 4, p1438-1459. 22p. 2015.

LAURENT, A.; GARAUDEL, P.; SCHMIDT, G.; EYNAUD, P. "Civil society meta-organizations and legitimating processes: The case of the addiction field in France." Voluntas: International Journal of Voluntary and Nonprofit Organizations, 31 (1), 19-38. 2020.

LIMA, I. B.; BUSZYNSKI, L. Local environmental governance, public policies and deforestation in Amazonia. Management of Environmental Quality: An International Journal, v. 22, n. 3, p. 292-316. 2011.

LOVEJOY, T.E; NOBRE, C. Amazon Tipping Point. Science Advances. 4(2), eaat2340. 2018.

MAIR, J., WOLF, M.; SEELOS, C. "Scaffolding: A process of transforming patterns of inequality in smallscale societies." Academy of Management Journal, 59 (6), 2021-2044. 2016.

MALETS, O. Book Review: Göran Ahrne and Nils Brunsson: Meta-organizations: 2008, Cheltenham: Edward Elgar. Organization Studies, 31(12), 1740-1744. 2010.

MENDES, A.D. A invenção da Amazônia. Alinhavos para uma história de futuro. 3a edição revista e aumentada. Belém: Banco da Amazônia; Universidade Federal do Pará, 2006. 
MITSCHEIN, T.A.; ROCHA, G.de M.; VASCONCELLOS SOBRINHO, M. Desenvolvimento Local e o Direito à Cidade na Floresta Amazônica. 1. ed. Belém: NUMA/UFPA, 2013. 142p.

NEPSTAD D, et al. The end of deforestation in the Brazilian Amazon. Science. 326:1350-1351. 2019.

PEIXOTO, I.; TEMMES, A.: "Market organizing in the European Union's biofuels market: Organizing for favouring, acceptability, and future preferences." Journal of Cleaner Production, 236, 117476. 2019.

RADNEJAD, A.B; VREDENBURG, H; WOICESHYN, J. Meta-organizing for open innovation under environmental and social pressures in the oil industry. Technovation, v. 66-67, August 2017, p.14-27. 2017.

SACHS, I. Amazônia: laboratório de biocivilizações do futuro, 2008. Disponível em: http://dowbor.org/2008/10/amazonia-laboratorio-de-biocivilizacoes-do-futuro-outubro-2008- 2.html/. 2017.

SANTILLI, M.; MOUTINHO, P. O desmatamento na Amazônia e a efetividade do Protocolo de Quioto. Revista Ciencia \& Ambiente, Santa Maria-RS, v. 32, p. 61-71. 2006.

SELSKY, J.W.; PARKER, B. "Cross-sector partnerships to address social issues: Challenges to theory and practice". Journal of Management, 31 (6), 849-873. 2005.

SOUSA, Y.M.; VASCONCELLOS, A.M.A.; VASCONCELLOS, M. Limites, Possibilidades e Dificuldades de Gestão Social em Redes de Cooperação para o Desenvolvimento Local. Cadernos Gestão Social, v. 3, p. 235-250, 2012.

SOUSA, Y.M.; FISCHER, T.M.D.; VASCONCELLOS, A.M.A. Os Conselhos Municipais e o Mrosc Enquanto Instrumentos Democratizantes para Transformações Políticas e Desenvolvimento Local. Amazônia, Organizações e Sustentabilidade, v.4, p. 93-107, 2015.

TRANFIELD, D.; DENYER, D.; SMART, P. Towards a methodology for developing evidence-informed management knowledge by means of systematic review. British Journal of Management, 14(3), 207-222. 2003.

VALE, J.; RIBEIRO, J.; BRANCO, M.C. Individual intellectual capital versus collective intellectual capital in a meta-organization. Journal of Intellectual Capital. Vol. 17 p. 279-297. 2016.

VALENTE, M.; OLIVER, C. Meta-Organization Formation and Sustainability in Sub-Saharan Africa. Organization Science 29 (4) 678-701, 2018.

VIFFEL, A.C.; THEDVALL, R. Organizing for social sustainability: governance through bureaucratization in meta-organizations. Sustaintability: Science, Practice and Policy. Vol. 8 (1), 2012.

ZHAO, E.Y.; WRY, T. Not all inequality is equal: Decomposing the societal logic of patriarchy to understand microfinance lending to women. Academy of Management Journal, 59 (6), 1994-2020. 2016.

ZYZAK, B.; JACOBSEN, D.I. External managerial networking in meta-organizations. Evidence from regional councils in Norway. Public Management Review. Volume 22, (9). 2020. 